\title{
Hydrogen mobility in transition zone silicates
}

\author{
${\text { Razvan } \text { Caracas }^{1 *} \text { (D) and Wendy R. Panero }}^{2}$
}

\begin{abstract}
We study the hydrogen mobility in ringwoodite and wadsleyite considering multiple charge-balanced defects, including $\mathrm{Mg}<=>2 \mathrm{H}, \mathrm{Si}<=>\mathrm{Mg}+2 \mathrm{H}$, and the hydrogarnet defect, $\mathrm{Si}<=>4 \mathrm{H}$, using molecular dynamics simulations based on the density functional theory at transition zone pressures and temperatures between 1500 and $2500 \mathrm{~K}$. We determine the diffusion coefficients and study in detail the mechanism of hydrogen mobility during lengthy simulations. Our results show that temperature, water concentration, and defect mechanism have a significant effect on mobility. We find that the fastest diffusion is for the $\mathrm{Mg}<=>2 \mathrm{H}$ defect, while $\mathrm{H}$ is more mobile when incorporated as $\mathrm{Si}<=>\mathrm{Mg}+2 \mathrm{H}$ than as hydrogarnet defects. The computed diffusivities for ringwoodite are larger than for wadsleyite: at $2000 \mathrm{~K}$, diffusivity is $1.13 \times 10^{-09} \mathrm{~m}^{2} / \mathrm{s}$ for ringwoodite compared to $0.93 \times 10^{-09} \mathrm{~m}^{2} / \mathrm{s}$ for wadsleyite. In general, the hydrogen atoms spend on the order of tens of picoseconds or more trapped in or around the vacancy sites with net migration between sites over timescales of tens of femtoseconds. At $2500 \mathrm{~K}$, some of these hydrogen excursions take place over several angstroms, while at $2000 \mathrm{~K}$, they do not always result in net diffusion. At $1500 \mathrm{~K}$, most of the defects fail to make excursions from their defect sites resulting in diffusion.
\end{abstract}

Keywords: Diffusion, Transition zone, Wadsleyite, Ringwoodite, Transport, Electrical conductivity, Defects, Hydrogen

\section{Introduction}

The incorporation of water in major mantle minerals affects the physical properties of these minerals, even with low concentrations of water. The introduction of water as hydrogen defects reduces seismic wave velocities (e.g., Jacobsen and Smyth 2006), enhances deformation (Kavner 2003), and increases electrical conductivity (Huang et al. 2005; Yoshino et al. 2009).

The transition zone is dominated by polymorphs of olivine, in which wadsleyite $(I 2 / \mathrm{m})$ is stable from $410-520 \mathrm{~km}$ depth, transforming to ringwoodite $(F d 3 m)$, stable from 520-660 km depth. As synthesized in the laboratory, each of these polymorphs can store water in excess of $2 \mathrm{wt} \%$, making them the primary focus for detecting water in the deep mantle. Wadsleyite incorporates hydrogen predominantly through $\mathrm{Mg}<=>2 \mathrm{H}$ defects (Smyth et al. 1997) while ringwoodite accommodates hydrous defects through multiple defect mechanisms, dominated by the same $\mathrm{Mg}<=>2 \mathrm{H}$ defect, but also with the hydrogarnet

\footnotetext{
* Correspondence: razvan.caracas@gmail.com

${ }^{1}$ CNRS, Ecole Normale Supérieure de Lyon, Université Claude Bernard Lyon 1, Laboratoire de Géologie de Lyon, CNRS UMR 5276, Lyon, France Full list of author information is available at the end of the article
}

defect, $\mathrm{Si}<=>4 \mathrm{H}$, and minor $\mathrm{Si}<=>\mathrm{Mg}+2 \mathrm{H}$ (Panero 2010; Panero et al. 2013).

The amount of water actually stored in the transition zone, however, may be significantly less than the total capacity. While an inclusion of ringwoodite in diamond suggests that localized regions of hydrated ringwoodite are possible (Pearson et al. 2014), seismic velocity and phase boundaries (Houser 2016) and electrical conductivity of the transition zone are more consistent with a mantle significantly undersaturated in water.

Electrical conductivity of the Earth's mantle varies significantly with depth and tectonic regime, including in the transition zone, in which the conductivity at the base of the transition zone is greater than the upper part of the transition zone (e.g., Kelbert et al. 2009; Shimizu et al. 2010). This variability is likely a complex function of temperature, composition (particularly $\mathrm{H}, \mathrm{Fe}$, and redox), and tectonic history. Indeed, the electrical conductivity of ringwoodite and wadsleyite vary as a function of water and iron content (e.g., Huang et al. 2005; Yoshino et al. 2009), with likely significant contributions from both proton and polaron conductivities. While disagreement remains as to the absolute values of conductivity in these 
materials, the electrical conductivity of hydrous ringwoodite is consistently found to be greater than hydrous wadsleyite for comparable water contents and experimental conditions but with different dependencies on absolute water content.

Direct measurements of hydrogen diffusivity in wadsleyite and ringwoodite under transition zone pressures and conditions are limited (Hae et al. 2006; Ohtani and Zhao 2009; Sun et al. 2015), in which these measurements include the complicating effects of iron that appears to enhance electrical conductivity through proton-polaron exchange mechanisms. The hydrogen diffusivity data are consistent with the electrical conductivity in which the $\mathrm{H}$ conductivity in ringwoodite exceeds that of wadsleyite.

We therefore calculate the diffusivity of hydrogen in ringwoodite at mantle-relevant conditions from ab initio molecular dynamics. While this is a well-established standard technique for melts and fluids (e.g., Tse 2002; Schweiger et al. 2008; Mookherjee et al. 2008), it is an unusual approach for solids due to the length of required calculations for appropriate statistics. For the latter, the large majority of the previous calculations (e.g., Bunson et al. 1999; Ammann et al. 2011) instead resolved to determine the activation energy along an assumed diffusion path, which combined with the concentration of vacancies, allowed to estimate the diffusion coefficients. Our approach is more daring: we insert hydrogen in the structures as defects in exchange for cations and obtain the self-diffusion coefficients directly from long molecular dynamics simulations; consequently, we also capture the diffusion path.

With these considerations, we investigate in detail the mobility of hydrogen in ringwoodite as a function of temperature, defect mechanism, and defect geometry. We compare our results to calculations in wadsleyite and further consider the effects of shear and strain on wadsleyite. We also examine the pathway through which hydrogen diffuses to suggest the consequences of interactions with point defects and dislocations in hydrogen diffusivity. We estimate the effect of hydrogen on the electrical conductivity of the major minerals of the Earth's transition zone through the Nernst-Einstein relation and assess the contribution of hydrogen to the measured mantle conductivity.

\section{Methods/experimental}

We perform first-principles molecular dynamics simulations. We allow the atoms to move in a crystal according to the Newtonian dynamics (molecular dynamics) under the action of interatomic forces computed within the density functional theory (DFT) (first principles). We use the planar-augmented wavefunction (PAW) formulation (Blochl 1994) of the DFT the VASP implementation (Kresse and Hafner 1993; Kresse and Joubert 1999) to compute the forces. The exchange-correlation energy is expressed in the Perdew-Burke-Ernzerhof form (Perdew et al. 1996) of the generalized gradient approximation. We employ a $500 \mathrm{eV}$ cutoff for the kinetic energy, $700 \mathrm{eV}$ for the augmented cutoff, and the $\Gamma$ point to sample the reciprocal space.

We use isokinetic NVT ensembles, where the velocity of the atoms is rescaled at each time step to fit the temperature, $T$, at fixed volume, $V$, and number of atoms, $N$, in the simulation box. The isokinetic NVT can be seen as an extreme version of the Nose-Hoover thermostat where the oscillation period of the temperature is set to the time step. We perform the simulations at volumes corresponding to transition zone pressures.

In all our calculations, we allow for long simulation times, between 70 and 200 ps at each condition with a time step of $1 \mathrm{fs}$. A 70 ps simulation requires the equivalent of about 500 processor days of computing time.

For ringwoodite, we consider several hydrogen incorporation mechanisms (Panero 2010): $\mathrm{Mg}^{2+}<=>2 \mathrm{H}^{+}, \mathrm{Si}^{4+}$ $<=>\mathrm{Mg}^{2+}+2 \mathrm{H}^{+}$, and the hydrogarnet substitution, $\mathrm{Si}^{4+}$ $<=>4 \mathrm{H}^{+}$. We consider two different $\mathrm{H} / \mathrm{O}$ atomic ratios per simulation cell: $1 / 32$ and $2 / 32$ each in two different geometries: a $2 \times 1 \times 1$ supercell of the conventional cell and a $2 \times 2 \times 2$ supercell of the primitive cell, with 16 $\mathrm{Mg}_{2} \mathrm{SiO}_{4}$ formula units. The simulations are run at 1500 , 2000 , and $2500 \mathrm{~K}$ with the same initial specific volume of ringwoodite, corresponding to about $25 \mathrm{GPa}$. Temperature and the substitution mechanisms affect the actual pressure of the simulations, but in all cases, the pressure remains in an interval of about 23 to $33 \mathrm{GPa}$. Over this pressure range, we do not expect the values of the diffusivity to change significantly.

We compare the ringwoodite diffusivities to the $\mathrm{Mg}^{2+}$ $<=>2 \mathrm{H}^{+}$defect on the M3 site in wadsleyite, the only active defect mechanism (Tsuchiya and Tsuchiya 2009), in a simulation box of one unit cell, or eight molecular units. To accelerate the diffusion, we also study the effect of strain. In order to compensate for the smaller simulation sizes, the simulation times of wadsleyite are longer, on the order of $100 \mathrm{ps}$.

The diffusion coefficient of hydrogen, $D_{0}$, in each calculation is obtained as the slope of the mean square displacements, MSD, as a function of time:

$$
D=\operatorname{MSD} / 6 t
$$

where, $t$ is time, and 6 is a geometric factor describing motion in three dimensions. MSD is the mean square displacement defined as:

$$
\operatorname{MSD}=<\left[r(t)-r\left(t_{0}\right)\right]^{\wedge} 2>
$$

Where $r(t)$ is the position in three-dimensional space at time, $t$. MSD is computed after an initial variable 
thermalization type of at least $2 \mathrm{ps}$, and $t-t_{0}$ window glides over the entire remaining simulation time. Values less than $\sim 1.0 \times 10^{-10} \mathrm{~m}^{2} / \mathrm{s}$ are an indication that the hydrogen atoms jump on a timescale similar to or greater than the total simulation time, and we include diffusivities for calculations only when the MSD is a linear function of time. Otherwise, we interpret that there are insufficient statistics to obtain reliable diffusion coefficients.

The diffusivity is a function temperature and can be modeled with $D_{0}$ as prefactor and the activation enthalpy $H$,

$$
D=D_{0} \exp (-H / R T)
$$

Where $R$ is the gas constant and $T$ is temperature in Kelvin.

We estimate the contribution proton conductivity makes to the apparent electrical conductivity, $\sigma$, with the Nernst-Einstein relation,

$$
\sigma=\left(F^{2} / R\right)\left(D q^{2} c / T\right)
$$

where $F$ is Faraday's constant, $q$ is the charge on the ion $(+1)$, and $c$ is concentration.

\section{Results and discussion}

Typical mean square displacement plots as a function of time are shown in Fig. 1 at both 2000 and 2500 K. Other MSD plots at $2000 \mathrm{~K}$ show larger irregularities; in those cases only the slope in the second half of the diagram was considered, which is linear. If the MSD is unchanging with time (e.g., for $\mathrm{Mg}, \mathrm{Si}$, and $\mathrm{O}$ in Fig. 1), this was a sign for no diffusion during the duration of our simulation and those points were discarded.

Table 1 summarizes the diffusion results of all the simulations performed for the $\mathrm{Mg}^{2+}<=>2 \mathrm{H}^{+}, \mathrm{Si}^{4+}<=>$ $\mathrm{Mg}^{2+}+2 \mathrm{H}^{+}$, and $\mathrm{Si}^{4+}<=>4 \mathrm{H}^{+}$substitutions in ringwoodite and different $\mathrm{H}$ concentrations, and 2000 and $2500 \mathrm{~K}$, and for the $\mathrm{Mg}^{2+}<=>2 \mathrm{H}^{+}$substitution in wadsleyite, at 1500 and $2000 \mathrm{~K}$. There is no net diffusion in ringwoodite at $1500 \mathrm{~K}$. The calculations span a range of temperatures greater than the entire transition zone. For each simulation, we also indicate the average pressure of the constant volume calculations.

Based on the computed diffusion coefficients, we fit the prefactor $D_{0}$ and the activation enthalpy, $H$, for each defect mechanism, concentration and phase according to Eq. (3). The values are listed in Table 2. They should be taken with care, as pressure increases with temperature in these isochoric calculations.

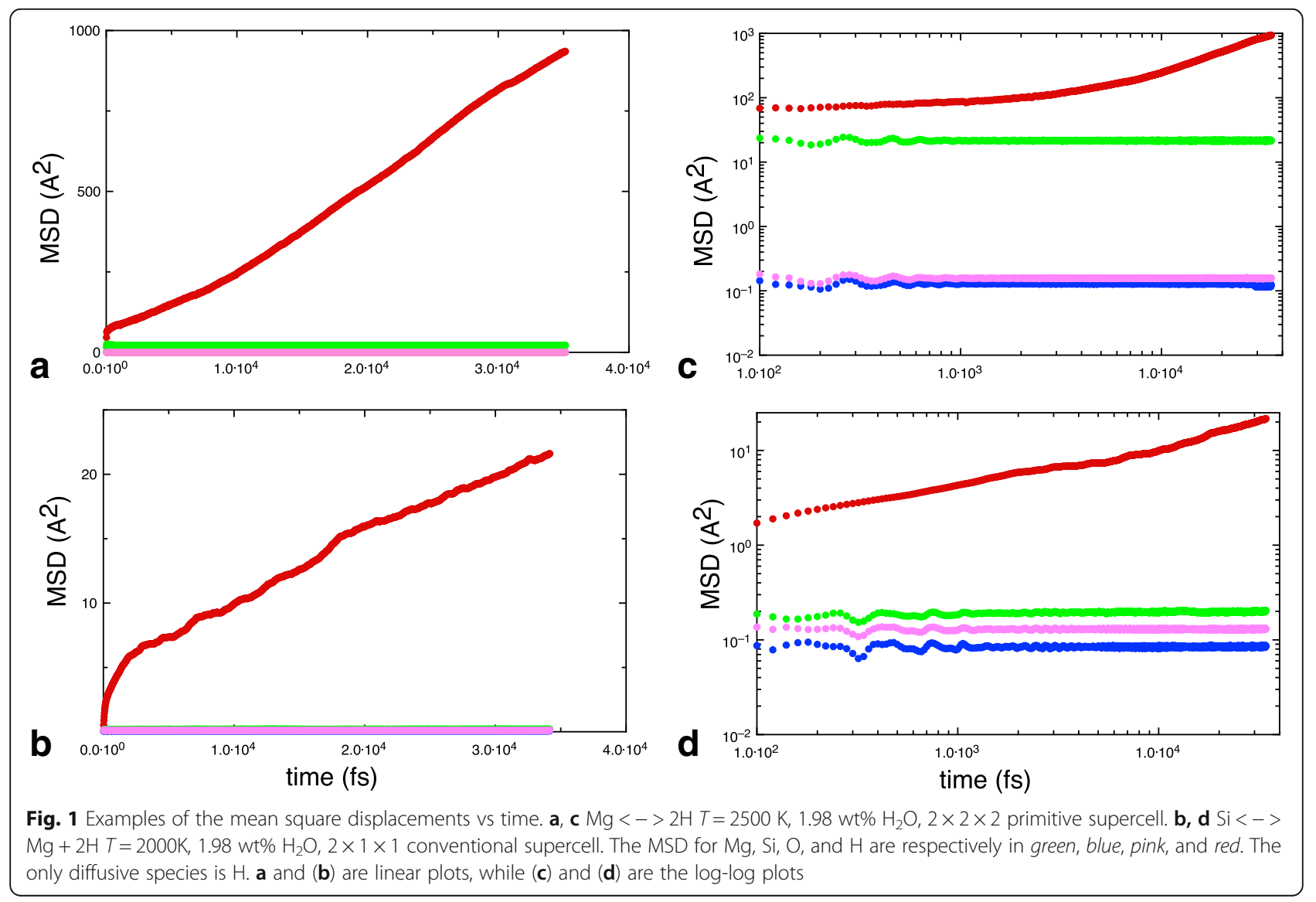


Table 1 Calculations on H-bearing ringwoodite and wadsleyite

\begin{tabular}{|c|c|c|c|c|c|c|c|c|}
\hline Defect & Mineral & $\mathrm{H} / \mathrm{O}$ ratio & $\mathrm{H}_{2} \mathrm{O} w t \%$ & Geometry & $P(\mathrm{GPa})$ & $T(K)$ & $D_{H}\left(10^{-9} \mathrm{~m}^{2} / \mathrm{s}\right)$ & $\log (\sigma)(S / m)$ \\
\hline \multirow[t]{10}{*}{$M g<=>2 H$} & \multirow[t]{10}{*}{$\mathrm{Rw}$} & $1 / 32$ & 0.81 & $2 \times 1 \times 1 C$ & 23.6 & 2000 & 0.569 & 0.03 \\
\hline & & $1 / 16$ & 1.63 & $2 \times 2 \times 2 P$ & 25.0 & 2000 & 1.132 & -1.12 \\
\hline & & $1 / 16$ & 1.63 & $2 \times 1 \times 1 C$ & 24.7 & 2000 & a & \\
\hline & & $1 / 32$ & 0.81 & $2 \times 2 \times 2 P$ & 25.1 & 2000 & a & \\
\hline & & $1 / 32$ & 0.81 & $2 \times 2 \times 2 P$ & 25.1 & 2000 & a & \\
\hline & & $1 / 32$ & 0.81 & $2 \times 1 \times 1 \mathrm{C}$ & 27.1 & 2500 & 8.215 & 1.09 \\
\hline & & $1 / 16$ & 1.63 & $2 \times 1 \times 1 \mathrm{C}$ & 26.8 & 2500 & 1.077 & 0.51 \\
\hline & & $1 / 32$ & 0.81 & $2 \times 2 \times 2 \mathrm{P}^{\mathrm{b}}$ & 27.0 & 2500 & 8.215 & 1.09 \\
\hline & & $1 / 32$ & 0.81 & $2 \times 2 \times 2 \mathrm{P}^{b}$ & 27.0 & 2500 & 10.005 & 1.18 \\
\hline & & $1 / 16$ & 1.63 & $2 \times 2 \times 2 P$ & 26.7 & 2500 & 43.727 & 2.12 \\
\hline \multirow[t]{4}{*}{$\mathrm{Si}<=>\mathrm{Mg}+2 \mathrm{H}$} & \multirow[t]{4}{*}{$\mathrm{Rw}$} & $1 / 32$ & 0.80 & $2 \times 1 \times 1 \mathrm{C}$ & 22.1 & 2000 & 0.217 & -0.40 \\
\hline & & $1 / 16$ & 1.60 & $2 \times 1 \times 1 \mathrm{C}$ & 24.6 & 2000 & 0.796 & 0.47 \\
\hline & & $1 / 32$ & 0.80 & $2 \times 1 \times 1 \mathrm{C}$ & 30.3 & 2500 & 2.698 & 0.60 \\
\hline & & $1 / 16$ & 1.60 & $2 \times 1 \times 1 C$ & 26.6 & 2500 & 5.448 & 1.20 \\
\hline \multirow[t]{4}{*}{$\mathrm{Si}<=>4 \mathrm{H}$} & \multirow[t]{4}{*}{$\mathrm{Rw}$} & $1 / 16$ & 1.62 & $2 \times 1 \times 1 C$ & 24.0 & 2000 & 0.077 & -0.54 \\
\hline & & $1 / 8$ & 3.27 & $2 \times 1 \times 1 C$ & 25.2 & 2000 & 0.027 & -0.70 \\
\hline & & $1 / 16$ & 1.62 & $2 \times 1 \times 1 C$ & 32.6 & 2500 & 0.263 & -0.11 \\
\hline & & $1 / 8$ & 3.27 & $2 \times 1 \times 1 \mathrm{C}$ & 27.0 & 2500 & 0.263 & 0.20 \\
\hline \multirow{2}{*}{$\begin{array}{l}\mathrm{Mg}<=>2 \mathrm{H} \text { and } \\
\mathrm{Si}<=>\mathrm{Mg}+2 \mathrm{H}\end{array}$} & \multirow[t]{2}{*}{ Rw } & $1 / 16$ & 1.62 & $2 \times 2 \times 2 P$ & 28.0 & 2000 & 0.452 & 0.23 \\
\hline & & $1 / 16$ & 1.62 & $2 \times 2 \times 2 P$ & 29.8 & 2500 & 0.74 & 0.35 \\
\hline \multirow[t]{6}{*}{$\mathrm{Mg}<=>2 \mathrm{H}$} & \multirow[t]{6}{*}{ Wd } & $1 / 16$ & 1.63 & $1 \times 1 \times 1$ & 21.5 & 1500 & 0.024 & -0.94 \\
\hline & & $1 / 16$ & 1.63 & $\begin{array}{l}1 \times 1 \times 1 \\
5 \% \text { strain }\end{array}$ & 36.9 & 1500 & 0.003 & -1.80 \\
\hline & & $1 / 16$ & 1.63 & $\begin{array}{l}1 \times 1 \times 1 \\
7 \% \text { shear }\end{array}$ & 21.6 & 1500 & 0.107 & -0.29 \\
\hline & & $1 / 16$ & 1.63 & $\begin{array}{l}1 \times 1 \times 1 \\
11 \% \text { shear }\end{array}$ & 20.2 & 1500 & 0.617 & 0.47 \\
\hline & & $1 / 16$ & 1.63 & $1 \times 1 \times 1$ & 21.8 & 2000 & 0.926 & 0.52 \\
\hline & & $1 / 16$ & 1.63 & $1 \times 1 \times 1$ & 23.6 & 2500 & $88.43^{c}$ & 2.41 \\
\hline
\end{tabular}

Summary of all the simulations performed on ringwoodite $(\mathrm{R})$ and wadsleyite $(\mathrm{W})$. Temperatures $(\mathrm{T})$ and pressures $(\mathrm{P})$ are also indicated. The $2 \times 1 \times 1 \mathrm{C}$ and $2 \times$ $2 \times 2 \mathrm{P}$ geometries represents supercell of the respectively Conventional and Primitive unit cells of ringwoodite

$R w$ ringwoodite structure, $W d$ wadsleyite structure

${ }^{\text {a }}$ There is no net diffusion observed during the duration of the simulation

${ }^{\mathrm{b}}$ The two values are for two different simulations

'Wadsleyite at $2500 \mathrm{~K}$ is molten; the value is given here only as reference

Table 2 Hydrogen diffusivity

\begin{tabular}{|c|c|c|c|c|c|c|}
\hline Defect & Mineral & $\mathrm{H} / \mathrm{O}$ ratio & $\mathrm{H}_{2} \mathrm{O} w t \%$ & Geometry & $D_{0}\left(\mathrm{~m}^{2} / \mathrm{s}\right)$ & $\mathrm{H}(\mathrm{k} / \mathrm{mol})$ \\
\hline \multirow[t]{2}{*}{$\overline{M g}<=>2 \mathrm{H}$} & $\mathrm{R}$ & $1 / 16$ & 1.63 & $2 \times 2 \times 2 P$ & 9.73E-02 & 303.8 \\
\hline & & $1 / 32$ & 0.81 & $2 \times 1 \times 1 C$ & 4.16E-04 & 224.5 \\
\hline \multirow[t]{2}{*}{$\mathrm{Si}<=>\mathrm{Mg}+2 \mathrm{H}$} & $\mathrm{R}$ & $1 / 16$ & 1.60 & $2 \times 1 \times 1 C$ & 1.19E-05 & 159.9 \\
\hline & & $1 / 32$ & 0.80 & $2 \times 1 \times 1 C$ & $6.44 \mathrm{E}-05$ & 209.5 \\
\hline \multirow[t]{2}{*}{$\mathrm{Si}<=>4 \mathrm{H}$} & $\mathrm{R}$ & $1 / 8$ & 1.62 & $2 \times 1 \times 1 C$ & 5.05E-04 & 260.9 \\
\hline & & $1 / 16$ & 3.27 & $2 \times 1 \times 1 C$ & $2.26 \mathrm{E}-06$ & 188.3 \\
\hline $\mathrm{Mg}<=>2 \mathrm{H}$ and $\mathrm{Si}<=>\mathrm{Mg}+2 \mathrm{H}$ & $\mathrm{R}$ & $1 / 16$ & 1.62 & $2 \times 2 \times 2 P$ & $5.32 \mathrm{E}-04$ & 232.4 \\
\hline $\mathrm{Mg}<=>2 \mathrm{H}$ & W & $1 / 16$ & 1.63 & $1 \times 1 \times 1$ & $5.62 \mathrm{E}-05$ & 183.2 \\
\hline
\end{tabular}

Diffusivity fits to the computed diffusion coefficients 
The hydrogen atoms typically spend several tens of picoseconds in one given cation vacancy site in between the diffusion jumps. The shape of their local trajectory depends on this site. Diffusion is realized in rapid $(<100 \mathrm{fs})$ transfers between stable defect sites. During a time that is on the order of up to a tenth of a picosecond, the hydrogen atoms may undergo an excursion that can be up to several angstroms long. There are cases, especially at low temperature $(1500 \mathrm{~K})$ when the outcome of such an excursion is cut short and the atoms return to the initial cage. But at 2000 and $2500 \mathrm{~K}$, most of these excursions result in a net displacement. This is the mechanism of the diffusion. The diffusion trajectory is a function of defect.

\section{$\mathrm{H}$ migration in ringwoodite}

In ringwoodite, the hydrogen atoms that are part of the $\mathrm{Si}<=>4 \mathrm{H}$ defects and the $\mathrm{Si}<=>\mathrm{Mg}+2 \mathrm{H}$ defects rapidly switch between the predicted lowest energy positions on the outside face of each polyhedron, generally maintaining maximum distance between the hydrogen atoms associated with each defect. Their trajectory results in apparent crosses on the faces of the tetrahedra (Figs. 2 and 3).

Figure 2 shows a part of the trajectories of the four $\mathrm{H}$ atoms that substitute one $\mathrm{Si}$ atom for the $\mathrm{Si}<=>4 \mathrm{H}$ defect. The $\mathrm{H}$ atoms remain around the initial vacancy. After $11 \mathrm{ps}$ in the simulation one of them exits the vacancy, moves away around an $\mathrm{O}$ atom (Fig. 2) to be trapped in an empty adjacent octahedron, inside which it moves around describing a donut shape. Finally, the $\mathrm{H}$ atom undergoing the excursion falls back into a $\mathrm{Si}$ vacancy close to the other three hydrogen atoms but situated at a distance of one unit cell from the initial defect. During this time, it covers the equivalent net distance of one lattice parameter. The case analyzed here corresponds to one substituted $\mathrm{Si}$ in a $2 \times 1 \times 1$ conventional supercell. As expected, the $\mathrm{H}$ diffuses along the shortest path, the $y$ - or $z$-axis. In Fig. 2b, c, it is clearly seen a diffusion pattern similar to a channel. An increase in temperature by $500 \mathrm{~K}$ leads to an increase in diffusion by more than one order of magnitude.

In case of the $\mathrm{Si}<=>\mathrm{Mg}+2 \mathrm{H}$ substitution, an excess $\mathrm{Mg}$ lies on the $\mathrm{Si}$ vacancy site; the $\mathrm{H}$ atoms are on the outer parts of the $\mathrm{SiO}_{6}$ tetrahedra. The pathway to initiate diffusion passes through an empty interoctahedral space. Not all $\mathrm{H}$ excursions result in net diffusion (Fig. 3) at $2000 \mathrm{~K}$.

For the $\mathrm{Mg}<=>2 \mathrm{H}$ defect mechanism, the hydrogen atoms migrate rapidly within a plane of the vacant $\mathrm{Mg}$ octahedron defined by the direction perpendicular to the edge-sharing $\mathrm{Mg}$ octahedra and sub-parallel to the plane defined by corner-sharing Si tetrahedra (Fig. 4) mapping out a "donut" shape about the octahedral vacancy. This plane reflects the crystallographic equivalent sites with the lowest energy positions as predicted by Panero (2010). The pair of hydrogen atoms is oriented such that their distance to the neighboring Mg octahedra is maximized, which also carry a positive charge. The actual trajectory is easily identified due to its donut shape.

All $\mathrm{Mg}<=>2 \mathrm{H}$ defects exchange $\mathrm{H}$ atoms during the course of the simulations; their diffusion paths follow not only the directions of the unit cell axis, as in the cases discussed above, but also along a diagonal.

Finally, the simulation of two adjacent defects of different types $(\mathrm{Mg}<=>2 \mathrm{H}$ and $\mathrm{Si}<=>\mathrm{Mg}+2 \mathrm{H})$ in the $2 \times 2 \times 2$ primitive supercell shows how these defects interact. About 34.7 ps into the simulation, three hydrogen atoms are found around the $\mathrm{Mg}$ vacancy, and one $\mathrm{H}$ atom around the $\mathrm{Si}$ vacancy. Figure $5 \mathrm{a}$ shows the trajectory of the $\mathrm{Mg}$ atoms over about $0.8 \mathrm{ps}$ and a snapshot of the position of the other atoms before the diffusion jump. It is clearly seen that the defect $\mathrm{Mg}$ stays inside the Si vacancy. The same snapshot with the $\mathrm{H}$ trajectory over 2 ps is
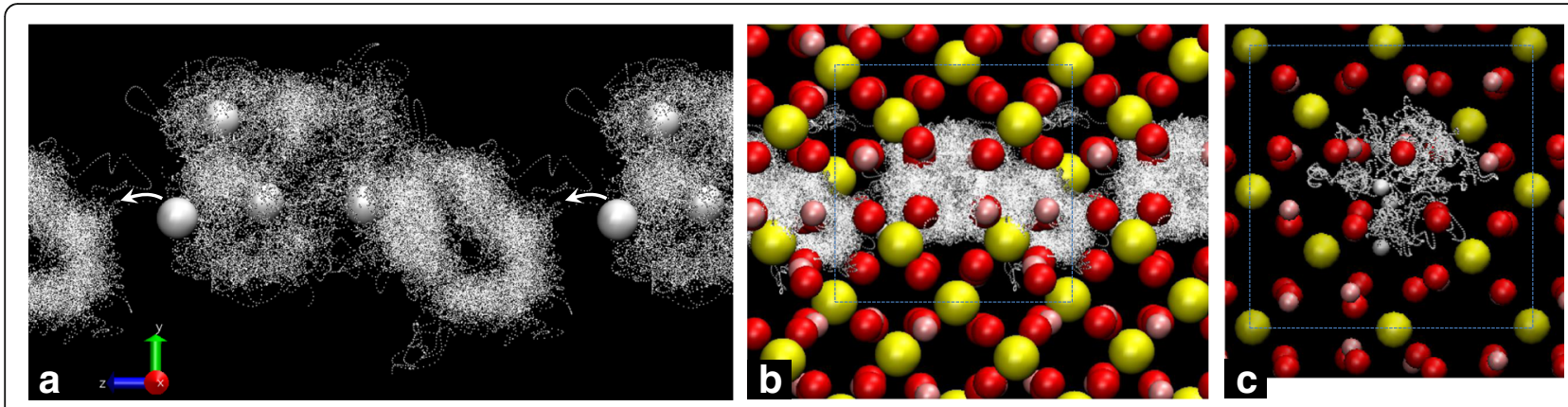

Fig. 2 Diffusion path of $\mathrm{H}$ for the $\mathrm{Si}<=>4 \mathrm{H}$ defect at $2500 \mathrm{~K} . \mathrm{Mg}$, Si, O, and $\mathrm{H}$ are represented respectively by pink, yellow, red, and white spheres. Sphere radii not to scale. The trajectory of the $\mathrm{H}$ atoms is shown with the dotted line over several picoseconds. a shows only the $\mathrm{H}$ trajectory for clarity. The diffusion path is shown in the context of the entire structure in (b) and (c). The hydrogen atoms occupy the Si vacancy. After escape, indicated by the white arrow, one of them described donut shapes while trapped in an empty octahedron, before falling into the neighboring Si vacancy and thus realizing a net proton transfer (a). The diffusion path describes channel-like patterns along the $z$-axis, as viewed in the image along $x$-axis (b) and $z$-axis $(\mathbf{c})$. The unit cell is outlined with dashed line 


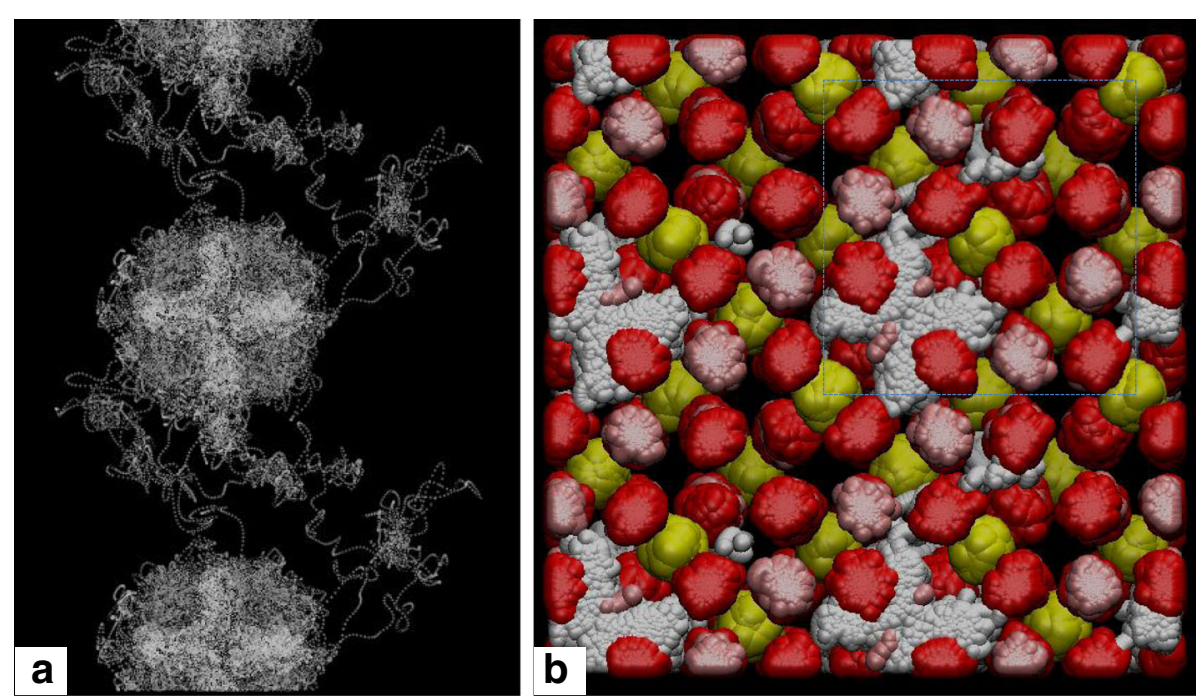

Fig. $3 \mathrm{H}$ diffusion for the $\mathrm{Si} \Leftrightarrow \mathrm{Mg}+2 \mathrm{H}$ defects at $2500 \mathrm{~K}$. They are computed in a $2 \times 1 \times 1$ convention supercell with one defect (a) and in a $2 \times$ $2 \times 2$ primitive supercell containing two defects (b). a Only the trajectory of $\mathrm{H}$ is shown, with all the other atoms omitted for clarity. $\mathrm{H}$ atoms describe crosses-like patterns on the outside parts of the $\mathrm{SiO}_{4}$ tetrahedra. $\mathrm{H}$ atoms undergo lengthy excursions before falling back into the vacancy site. $\mathbf{b}$ The trajectory described by all the atoms during $35 \mathrm{ps}$ is represented here. Pink, yellow, red and white represent respectively the Mg, $\mathrm{Si}, \mathrm{O}$, and $\mathrm{H}$ atoms. Not all excursions of $\mathrm{H}$ result in net diffusion, as seen from the defect in the lower left part of the image: $\mathrm{H}$ falls back into the initial site after escaping into the adjacent empty octahedron for a short time. The unit cell is outlined with dashed line

shown in Fig. 5b: the characteristic donut and cross shapes are clearly identifiable. One hydrogen atom is shown during its jump in snapshot in Fig. 5c. The jump requires just a few tens of femtoseconds. Eventually, the $\mathrm{H}$ falls into the neighboring vacancy, each of which containing now two $\mathrm{H}$ atoms (Fig. 5d). A similar but reverse process was responsible for obtaining the three $\mathrm{H}$ atoms in the $\mathrm{Mg}$ vacancy site. Figure $4 \mathrm{e}$ shows a 20 ps duration of trajectories of all the atoms from the same structural fragment.

\section{$\mathrm{H}$ migration in wadsleyite}

In wadsleyite, static calculations of $\mathrm{H}$ defects show that pairs of $\mathrm{H}$ in the $\mathrm{Mg}<=>2 \mathrm{H}$ defect tend to align with the $\mathrm{OH}$ dipoles parallel to the $z$-axis (Tsuchiya and Tsuchiya 2009). In our dynamical simulations at the lowest temperatures in our simulations ( $1500 \mathrm{~K})$, the $\mathrm{H}$ atoms explore the vacancy site, in trans positions. At $2000 \mathrm{~K}$, they escape easily from their initial sites and wander around to realize a net diffusion.

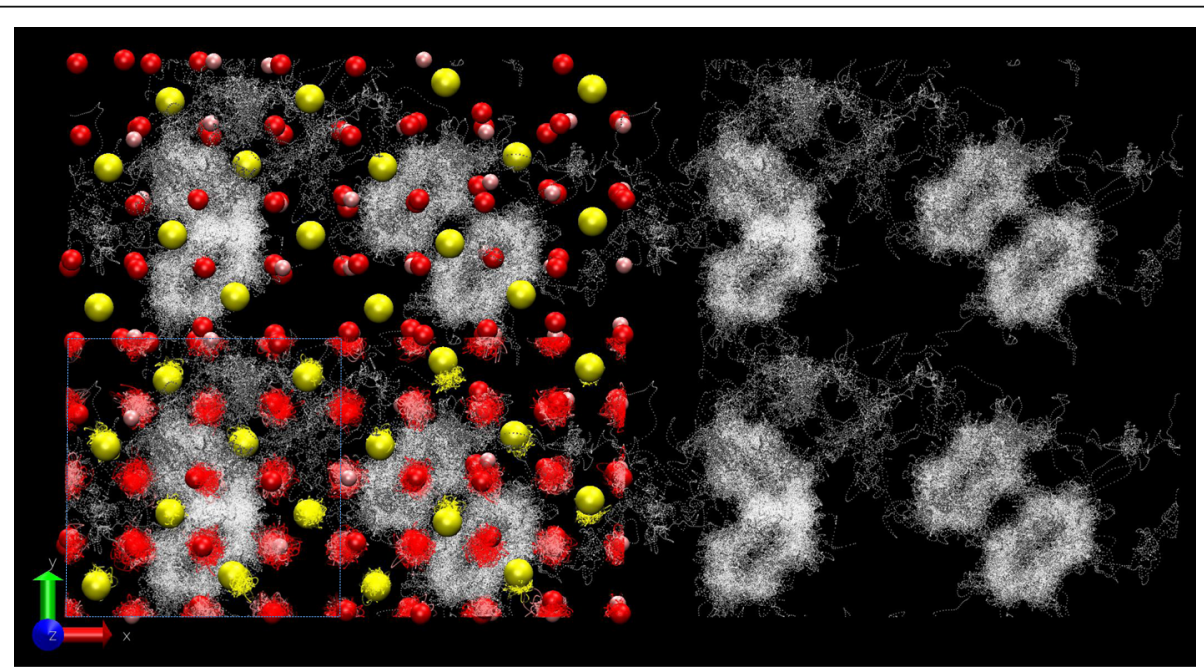

Fig. 4 Trajectory of the $\mathrm{H}$ atoms for the $\mathrm{Mg}<=>2 \mathrm{H}$ defect during about $35 \mathrm{ps}$. A structural fragment of $4 \times 2 \times 2$ unit cells is represented; on the right half all the atoms except for $\mathrm{H}$ are omitted for clarity. The example shown here is for a simulation at $2500 \mathrm{~K}$ with two defects in a $2 \times$ $2 \times 2$ primitive supercell. Pink, yellow, and red represent respectively the $\mathrm{Mg}$, Si, and $\mathrm{O}$ atoms. The unit cell is outlined with dashed line 

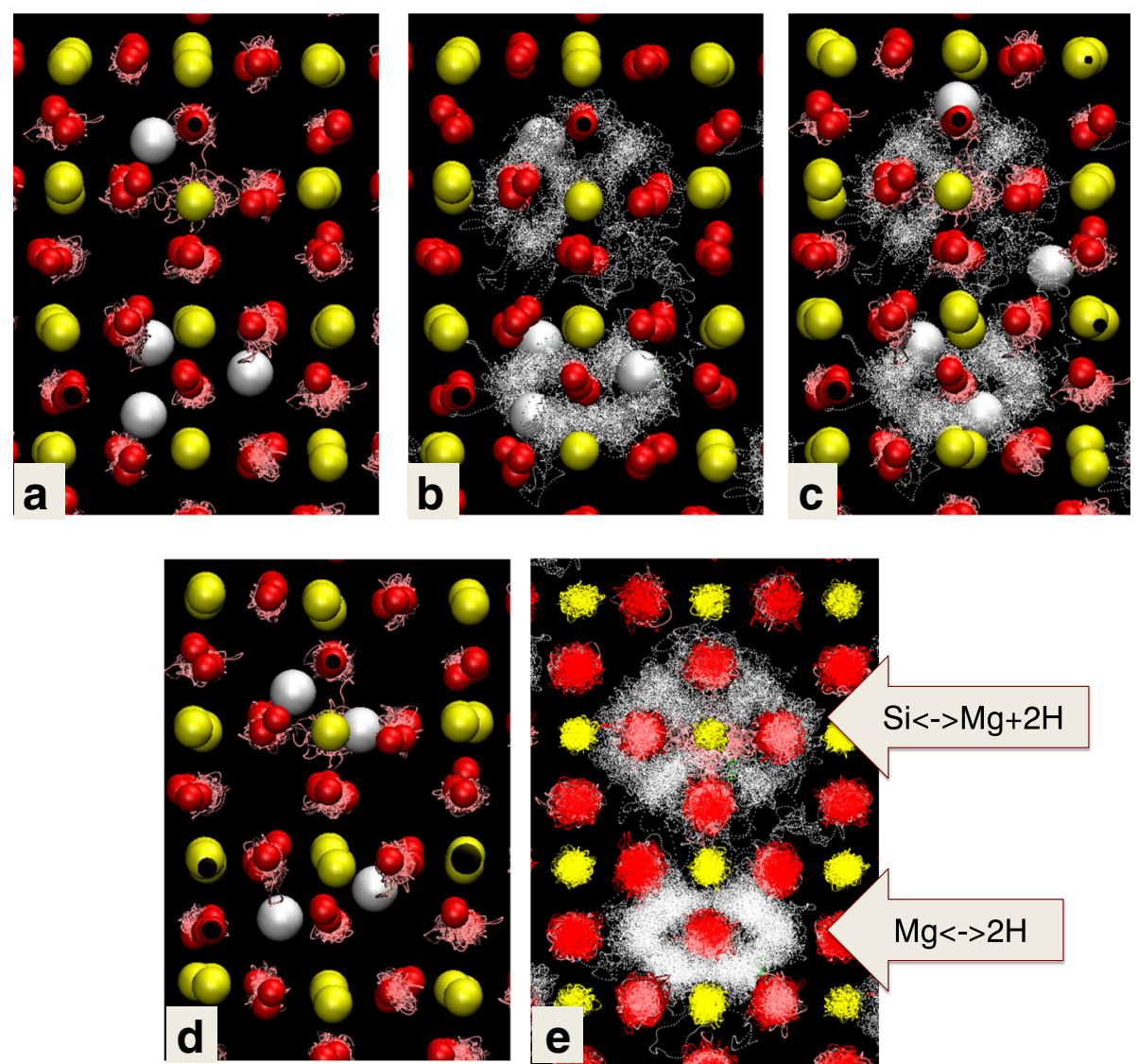

Fig. 5 Snapshots of the diffusion of hydrogen in a $2 \times 2 \times 2$ primitive supercell containing two defects at $2000 \mathrm{~K}$. Mg $<=>2 \mathrm{H}$ lies in the lower half of the image above and $\mathrm{Si}<=>\mathrm{Mg}+2 \mathrm{H}$ lies in the upper half. a A snapshot of the structure when $3 \mathrm{H}$ atoms occupy the Mg vacancy, $1 \mathrm{Mg}$ the Si vacancy, and one last $\mathrm{H}$ gravitates around the Si vacancy. The Mg atoms are represented with their trajectory (pink dotted lines) during half a picosecond. There is no diffusion of $\mathrm{Mg}$. $\mathbf{b}$ The $\mathrm{H}$ trajectory is donut- and cross-shaped in the respective two defects as represented over 2 ps simulation time. $\mathbf{c}$ One of the three $\mathrm{H}$ atoms escape the Mg vacancy. The excursion lasts several tens of femtoseconds. $\mathbf{d}$ The escaped $\mathrm{H}$ atoms falls around the Si vacancy. e Trajectory of all atoms during 20 ps of simulation time. The only diffusing species is $\mathrm{H}$

Comparable simulations on wadsleyite were performed in one unit cell, with eight formula units, so that water concentrations are comparable between the wadsleyite and ringwoodite simulations. The diffusion of hydrogen is realized in channel-like trajectories continuous along the $z$-axis and interconnected along the $y$-axis (Fig. 6). The $\mathrm{H}$ atoms, as in ringwoodite, diffuse by hopping between the $\mathrm{O}$ atoms and avoiding the $\mathrm{Mg}$ sites. They move around the $\mathrm{SiO}_{4}$ tetrahedra but prefer the vacant inter-tetrahedral space.

At $2500 \mathrm{~K}$ and $23.6 \mathrm{GPa}$ in wadsleyite (Table 1), MSD shows net displacements for all oxygen, silicon, and magnesium atoms in the structure, and therefore, we interpret that this calculation reflects a melt, consistent with the melting temperature of wadsleyite. The hydrogen diffusivity calculated in this simulation, $88.10^{-9} \mathrm{~m}^{2} /$ $\mathrm{s}$, then reflects the diffusivity of $\mathrm{H}$ in a molten system. Our hydrogen-bearing calculations show the presence of melt of lower temperatures than both previous freezing simulations on anhydrous liquid $\mathrm{Mg}_{2} \mathrm{SiO}_{4}$ (De Koker et al. 2008) and recent static experimental data (Liebske and Frost 2012) consistent with melting-point depression for hydrated materials.

\section{Energy considerations}

There is no obvious relation between the position of the hydrogen atoms along their diffusion path and the fluctuation in total energy of the system. There are examples when the local energy maximum corresponds to migration of one $\mathrm{H}$ atom between sites, but in these cases, the energy profile does not resemble that of a saddle point. Furthermore, the next local energy maximum corresponds to $\mathrm{H}$ inside or around its new host site. This behavior reflects the complex relationship between the position of all the atoms in the lattice and the total energy of the lattice, not just the hydrogen positions. The energy fluctuations that we compute include contributions from not only the position of the diffusing atoms but also the vibrational contributions. For example, Fig. 7a shows the fluctuations in total energy computed 


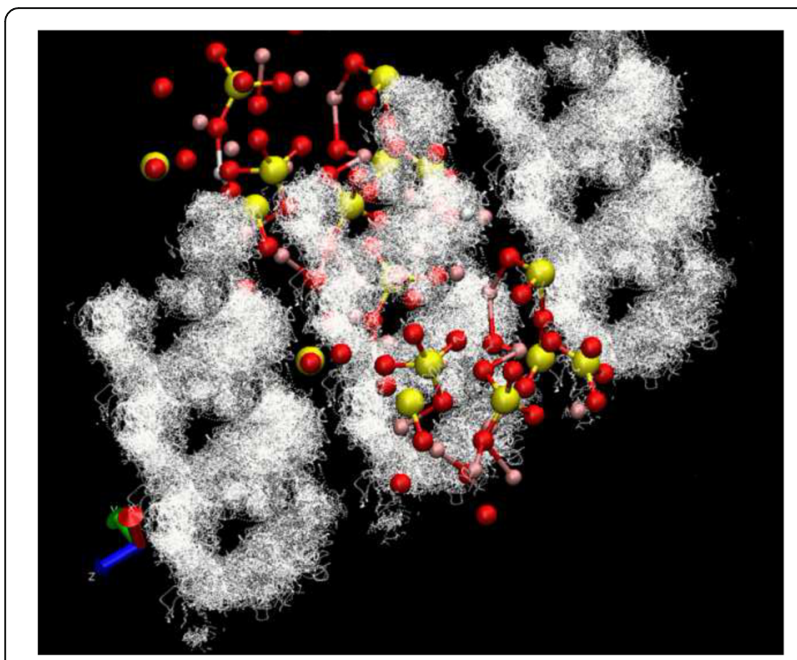

Fig. 6 Diffusion of $H$ in the wadsleyite structure at $2000 \mathrm{~K}$. The structural fragment shown here represents the $\mathrm{H}$ trajectories during 60 picoseconds after thermalization at $2000 \mathrm{~K}$ spanning several unit cells. The diffusion is realized in the (010) plane, containing the shortest lattice parameters

during several picoseconds for the $\mathrm{Si}<=>4 \mathrm{H}$ substitution in ringwoodite. These fluctuations are regularly observed during NVT simulations. Details in Fig. $7 \mathrm{~b}$ are shown prior, during, and after the escape of the $\mathrm{H}$ atom in the $\mathrm{Si}<=>4 \mathrm{H}$ substitution depicted in Fig. 2 and discussed in detail above. There is no clear relation between the position of the hydrogen atoms along the diffusion path and the total energy of the system. This

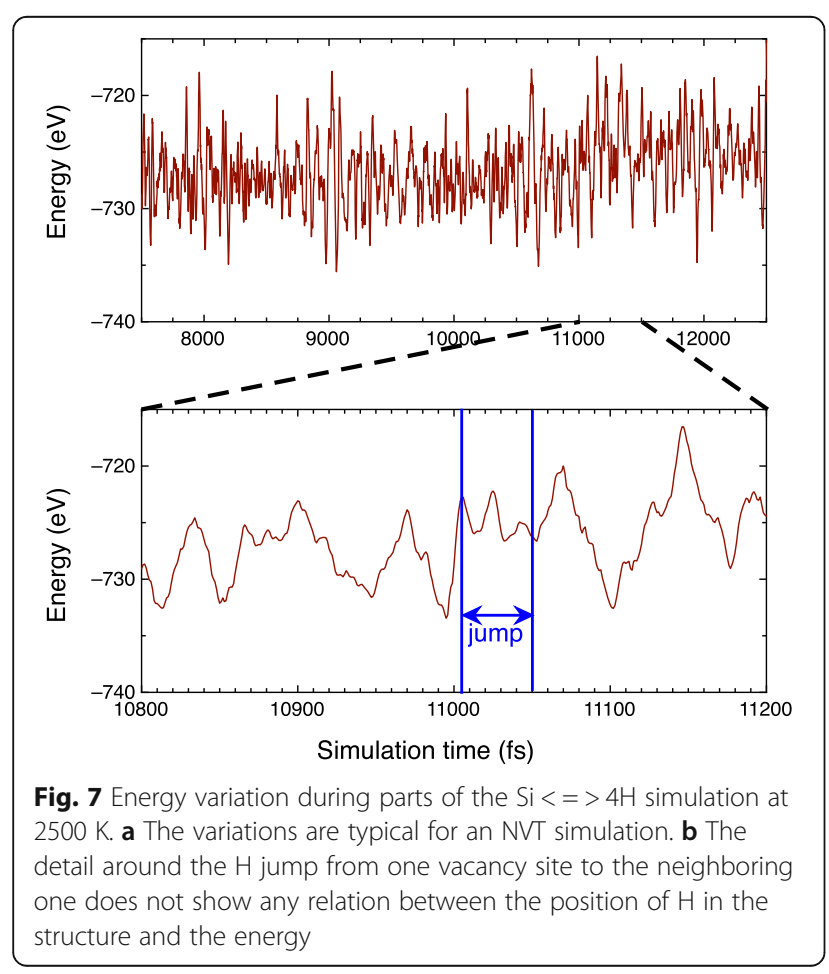

might also raise questions about the validity of the activation energy approach within a partially fixed lattice in static (i.e., $0 \mathrm{~K}$ ) or nudged-elastic band simulations.

\section{Factors affecting diffusion rate: phase, substitution} mechanism, concentration, and temperature

For ringwoodite, we find no statistically significant net migration of hydrogen at $1500 \mathrm{~K}$ in any of the calculations. Figure 8 shows the diffusion rates we obtained for each calculation in Table 1, with fits to Eq. (3) in Table 2. In ringwoodite, the $\mathrm{Mg}<=>2 \mathrm{H}$ defect leads to the greatest $\mathrm{H}$ diffusivities at both 2000 and $2500 \mathrm{~K}$ significantly increasing with increased water concentration. We find that the apparent diffusivity is greater in the $2 \times 2 \times 2$ primitive cell than in the $2 \times 1 \times 1$ conventional cell, and that for constant temperature and geometry, the diffusivity increases with increasing defect density. The largest values of diffusion are greater than $10^{-9} \mathrm{~m}^{2} /$ $\mathrm{s}$ at $2000 \mathrm{~K}$ and increase to $4.4 \times 10^{-8}$ at $2500 \mathrm{~K}$. Such high values of the $\mathrm{H}$ diffusion are comparable to the ones obtained in cold hydrous $\mathrm{MgSiO}_{3}$ silicate melts (Karki et al. 2010): on the order of $2 \times 10^{-8} \mathrm{~m}^{2} / \mathrm{s}$ at

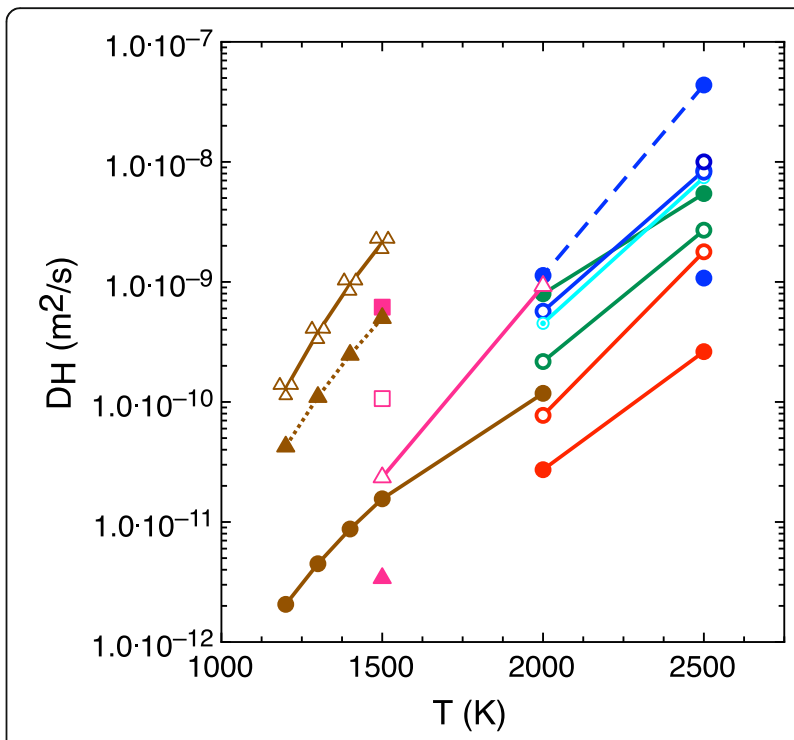

Fig. 8 Hydrogen diffusion coefficients in ringwoodite and wadsleyite as a function of temperature. $\mathrm{Mg}<=>2 \mathrm{H}, \mathrm{Si}<=>\mathrm{Mg}+2 \mathrm{H}$, and $\mathrm{Si}<=>$ $4 \mathrm{H}$ defect mechanisms are respectively plotted in blue, green, and red. Ringwoodite results are represented with one (open circles) and two (solid circles) defects per simulation supercell in the $2 \times 2 \times 2$ primitive (dashed lines) and $2 \times 1 \times 1$ conventional (solid lines) supercells. The combined $\mathrm{Mg}<=>2 \mathrm{H}$ and $\mathrm{Si}<=>\mathrm{Mg}+2 \mathrm{H}$ defects in the same $2 \times$ $2 \times 2$ supercell is shown with dotted circles. Wadsleyite is in purple: empty triangles for $\mathrm{Mg}<=>2 \mathrm{H}$ defect, empty squares with $7 \%$ shear, solid squares with 15\% shear, solid triangle with 5\% uniaxial strain. Brown circles are extrapolated experimental data from Sun et al. (2015) for ringwoodite, brown triangles from Hae et al. (2006) for wadsleyite. Triple empty triangles are for experiments in polycrystalline wadsleyite (Ohtani and Zhao 2009) 
$2500 \mathrm{~K}$ and $0 \mathrm{GPa}$, and $3 \times 10^{-8} \mathrm{~m}^{2} / \mathrm{s}$ at $3000 \mathrm{~K}$ and $20 \mathrm{GPa}$. This suggests that either solid hydrous ringwoodite at $2500 \mathrm{~K}$ is superheated or that the hydrous melts at $3000 \mathrm{~K}$ are supercooled.

Consistently, lower hydrogen diffusivities are found in the other two defects. Hydrogen in the $\mathrm{Si}<=>\mathrm{Mg}+2 \mathrm{H}$ defect diffuse faster at each temperature than hydrogen in $\mathrm{Si}<=>4 \mathrm{H}$ defects for all concentrations and supercell geometries calculated. Doubling the water content in each calculation changes the inferred hydrogen diffusivity by a factor of two but with opposite effect: it increases mobility of hydrogen associated with the $\mathrm{Si}<=>\mathrm{Mg}+2 \mathrm{H}$ defect yet decreases when associated with the $\mathrm{Si}<=>4 \mathrm{H}$ defect.

The simulations with the combined $\mathrm{Mg}<=>2 \mathrm{H}$ and $\mathrm{Si}<=>\mathrm{Mg}+2 \mathrm{H}$ defects yield diffusion coefficients that fall, as expected, between the equivalent concentration $\mathrm{Mg}<=>2 \mathrm{H}$ calculations and the $\mathrm{Si}<=>\mathrm{Mg}+2 \mathrm{H}$ calculations. While each defect is active in ringwoodite, the $\mathrm{Mg}$ $<=>2 \mathrm{H}$ defect is dominant, particularly at concentrations below $1 \mathrm{wt} \%$ (Panero et al. 2013). Therefore, as the mechanism with both the greatest hydrogen diffusivity and greatest concentration, we consider the diffusivity of hydrogen in the $\mathrm{Mg}<=>2 \mathrm{H}$ defect to control the diffusivity of hydrogen in ringwoodite.

The experimental hydrogen diffusion data for ringwoodite extrapolated to $2000 \mathrm{~K}$ falls in the middle of the range of values we obtained in our simulations (Ohtani and Zhao 2009; Sun et al. 2015). The inferred activation enthalpy in $2000-2500 \mathrm{~K}$ for ringwoodite in the fastest mechanism is $300 \mathrm{~kJ} / \mathrm{mol}$, significantly greater than the experimental value for iron-bearing polycrystalline and single-crystal ringwoodite, 140 and $101 \mathrm{~kJ} / \mathrm{mol}$, respectively. In contrast, the activation enthalpy in wadsleyite, $180 \mathrm{~kJ} / \mathrm{mol}$, is more similar to the polycrystalline, ironbearing experimental measurements in wadsleyite of $123 \mathrm{~kJ} / \mathrm{mol}$. The presence of iron, additional defects, or experimental strain may explain the difference. Our computed activation enthalpies are larger than the ones obtained from static simulations (Verma and Karki 2009), by almost one order of magnitude in case of ringwoodite. Table 2 lists the diffusivity fits to our computed diffusion coefficients.

For wadsleyite however, the extrapolated experimental data (Hae et al. 2006) are greater than our theoretical results. As with the Ohtani and Zhao (2009) data, these experiments are measured in an iron-bearing polycrystalline sample, which may explain their faster diffusivities values.

At $2000 \mathrm{~K}$, the $\mathrm{H}$ diffusion in wadsleyite for the $\mathrm{Mg}$ $<=>2 \mathrm{H}$ defect is $0.93 \times 10^{-9} \mathrm{~m}^{2} / \mathrm{s}$. This is $16 \%$ less than the fastest value of $1.13 \times 10^{-9} \mathrm{~m}^{2} / \mathrm{s}$ computed for ringwoodite for the same defect and at the same temperature, consistent to the experimental hydrogen diffusivity data (Hae et al. 2006; Ohtani and Zhao 2009) (Table 1).

To explore if the discrepancies with previously published diffusivities as discussed above are due to lattice strain, we calculated the diffusion under various systems of strains applied to the wadsleyite structure at $1500 \mathrm{~K}$. We found that a $5 \%$ uniaxial strain along the $x$-axis reduces the diffusivity by one order of magnitude according to the mean square-displacement analysis. However, as the values are already below $10^{-10} \mathrm{~m}^{2} / \mathrm{s}$, they do not show diffusion; rather, they reflect an enhancement of the $\mathrm{H}$ localization. When pure sheared is applied, the values increase by about one order of magnitude for $7 \%$ shear and almost two orders for $10 \%$ shear. It is only this last case where actual net hydrogen transfers between the lattice sites is observed. While large strain values are highly unlikely to exist in a natural setting, we show that residual strains in experiments may lead to an underestimate of diffusivity due to $\mathrm{H}$ localization.

\section{Electrical conductivity of the transition zone}

Finally, we use the Nernst-Einstein relation to obtain the electrical conductivity from the diffusion coefficients. The values are reported on the last column of Table 1 . They correspond to diffusivity inside single crystals.

The last column of Table 1 lists the computed conductivities for each simulation. For ringwoodite, the highest values computed at $2500 \mathrm{~K}$ are on the order of 1.1 to 2.1 $\log (\sigma)(\mathrm{S} / \mathrm{m})$. They correspond to the $\mathrm{Mg}<=>2 \mathrm{H}$ defect that dominate the transport properties. Values at $2000 \mathrm{~K}$ are one order of magnitude lower. For wadsleyite, the computed log values of the conductivity are on the order of $0.5 \log (\sigma)(\mathrm{S} / \mathrm{m})$ at $2000 \mathrm{~K}$.

Our values fall between the same order of magnitude down to two orders of magnitude below experimental values (Huang et al. 2005; Sun et al. 2015). This is most probably due to crystallinity: the diffusion along the grain boundaries plays a major role in the total transport. Measurements on real crystals show values order of magnitude higher as obtained for single crystal (Sun et al. 2015) than polycrystalline samples (Ohtani and Zhao 2009).

We conclude from our suite of calculations in ringwoodite that increased concentration of defects significantly enhances proton migration in the crystal, consistent with the concentration-dependent electrical conductivity (Huang et al. 2005). We find that hydrogen clearly rests in charge-neutral defect sites within the crystal for the majority of the simulation time, and therefore, it is the increased density of defects that leads to an increased conductivity through shortened hopping distance for the hydrogen. As with any diffusion-limited processes, the proton conductivity will be dominated by the fastest diffusing species, which in the case of 
ringwoodite, is the hydrogen atoms associated with the dominant $\mathrm{Mg}<=>2 \mathrm{H}$ defect.

We find that the associated inferred conductivity of ringwoodite is greater than that of wadsleyite at realistic mantle conditions. The computed values of the conductivity and the difference between ringwoodite and wadsleyite are fully consistent with an increase in conductivity at the base of the Earth's mantle (Kelbert et al. 2009; Shimizu et al. 2010) and may help signal the presence of significant ( 1 wt\%) water in the transition zone.

\section{Conclusions}

We study the main three mechanisms of incorporating hydrogen into the ringwoodite structure via chemical substitutions: $\mathrm{Mg}<=>2 \mathrm{H}, \quad \mathrm{Si}<=>\mathrm{Mg}+2 \mathrm{H}$, and the hydrogarnet defect, $\mathrm{Si}<=>4 \mathrm{H}$. We perform firstprinciples molecular dynamics simulations lasting up to a couple hundred picoseconds. Three $\mathrm{Mg}<=>2 \mathrm{H}$ calculations at $2000 \mathrm{~K}$ did not yield sufficient migration statistics to results in a reliable diffusivity in 200 ps of simulation time, which highlights that the starting conditions and the thermal history of the calculations may play a factor in the quantitative results.

We find that temperature and defect concentration increase the rate of the $\mathrm{H}$ diffusion. More isometric geometries, like the $2 \times 2 \times 2$ primitive supercell also show faster diffusion than more anisotropic, like the $2 \times$ $1 \times 1$ conventional supercell, similar to the reduction of diffusivity found in wadsleyite for $5 \%$ strain. We find that the $\mathrm{Mg}<=>2 \mathrm{H}$ defect mechanism yields the greatest $\mathrm{H}$ diffusion rates, with the hydrogarnet substitution, $\mathrm{Si}<=>4 \mathrm{H}$, showing the slowest diffusion.

During the simulation time of several tens of picoseconds, the $\mathrm{H}$ atoms travel over several lattice sites. However, during their path, they spend a considerable amount of time pinned in the defect sites. The diffusion is realized via jumps between the vacancy sites; during these jumps, the hydrogen atoms move around the neighboring $\mathrm{O}$ atoms, such as to continuously form $\mathrm{OH}$ bonds. They try to avoid at all cost the $\mathrm{Mg}$ cations, which are also positively charged; usually they stay in the void octahedral space. There is no obvious relation in the energy fluctuations during the simulations and the positions of the hydrogen atoms in the lattice-be they in the vacancy sites or during the diffusive jumps.

The $\mathrm{Mg}<=>2 \mathrm{H}$ defects are more mobile in ringwoodite than wadsleyite. This result agrees with the proton conductivity inferences of Yoshino et al. (2009) and Huang et al. (2005), as well as the observed increase in electrical conductivity with depth through the transition zone (e.g., Khan et al. 2011; Olsen 1998).

\section{Abbreviations}

MSD: Mean square displacements

\section{Acknowledgements}

The calculations were performed on the ADA machine at the IDRIS

Supercomputing Center, France, under eDARI grant ×2016106368.

\section{Funding}

RC was funded by the Extreme Physics and Chemistry directorate of the Deep Carbon Observatory. WRP was funded by NSF via grant EAR 09-55647.

\section{Authors' contributions}

RC and WRP proposed the topic, conceived and designed the study, analyzed the data, and constructed the manuscript. RC ran the calculations. Both authors read and approved the final manuscript.

\section{Competing interests}

The authors declare that they have no competing interests.

\section{Publisher's Note}

Springer Nature remains neutral with regard to jurisdictional claims in published maps and institutional affiliations.

\section{Author details}

${ }^{1}$ CNRS, Ecole Normale Supérieure de Lyon, Université Claude Bernard Lyon 1, Laboratoire de Géologie de Lyon, CNRS UMR 5276, Lyon, France. ${ }^{2}$ School of Earth Sciences, Ohio State University, Columbus, OH 43210, USA.

Received: 31 August 2016 Accepted: 27 February 2017

Published online: 29 March 2017

\section{References}

Ammann MW, Brodholt JP, Dobson DP (2011) Ferrous iron diffusion in ferro-periclase across the spin transition. Earth Planet Sci Lett 302:393-402. doi:10.1016/j.epsl. 2010.12.031

Blochl PE (1994) Projector augmented-wave method. Phys Rev B 50:17953-17979

Bunson PE, Di Ventra M, Pantelides ST, Schrimpf RD, Galloway KF (1999) Ab initio calculations of $\mathrm{H}^{+}$energetics in $\mathrm{SiO}_{2}$ : implications for transport. IEEE Trans Nuclear Sci 46:1568-1573

De Koker NP, Stixrude L, Karki BB (2008) Thermodynamics, structure, dynamics, and freezing of $\mathrm{Mg}_{2} \mathrm{SiO}_{4}$ liquid at high pressure. Geoch Cosmochimica Acta 72:1427-1441. doi:10.1016/j.gca.2007.12.019

Hae R, Ohtani E, Kubo T, Koyama T, Utada H (2006) Hydrogen diffusivity in wadsleyite and water distribution in the mantle transition zone. Earth Planet Sci Lett 243:141-148. doi:10.1016/j.epsl.2005.12.035

Houser C (2016) Global seismic data reveal little water in the mantle transition zone. Earth Planet Sci Lett 448:94-101. doi:10.1016/j.epsl.2016.04.018

Huang X, Xu Y, Karato SI (2005) Water content in the transition zone from electrical conductivity of wadsleyite and ringwoodite. Nature 434:746-749. doi:10.1038/nature03426

Jacobsen SD, Smyth JR (2006). Effect of water on the sound velocities of ringwoodite in the transition zone. Earth's Deep Water Cycle. In: Jacobsen SD, van der Lee S. Geophys Monogr Ser, vol. 168. pp. 131-145, AGU, Washington, DC

Karki BB, Bhattarai D, Mookherjee M, Stixrude L (2010) Visualization-based analysis of structural and dynamical properties of simulated hydrous silicate melt. Phys Chem Minerals 37:103-117

Kavner A (2003) Elasticity and strength of hydrous ringwoodite at high pressure. Earth Planet Sci Lett 214:645-654. doi:10.1016/50012-821X(03)00402-3

Kelbert A, Schultz A, Egbert G (2009) Global electromagnetic induction constraints on transition-zone water content variations. Nature 460:1003-1006

Khan A, Kuvshinov A, Semenov A (2011) On the heterogeneous electrical conductivity structure of the Earth's mantle with implications for transition zone water content. J Geophys Res Solid Earth 116:B01103. doi:10.1029/ 2010JB007458

Kresse G, Hafner J (1993) Ab initio molecular dynamics for liquid metals. Phys Rev B 47:558

Kresse G, Joubert D (1999) From ultrasoft pseudopotentials to the projector augmented-wave method. Phys Rev B 59:1758

Liebske C, Frost DJ (2012) Melting phase relations in the MgO-MgSiO3 system between 16 and 26GPa: implications for melting in Earth's deep interior. Earth Planet Sci Lett 345-348(C):159-170. doi:10.1016/j.epsl.2012.06.038

Mookherjee M, Stixrude L, Karki BB (2008) Hydrous silicate melt at high pressure. Nature 452:983-986 
Ohtani E, Zhao D (2009) The role of water in the deep upper mantle and transition zone: dehydration of stagnant slabs and its effects on the big mantle wedge. Russian Geol Geophys 50:1073-1078. doi:10.1016/j.rgg. 2009.11.006

Olsen N (1998) The electrical conductivity of the mantle beneath Europe derived from C-responses from 3 to $720 \mathrm{hr}$. Geophys I Int 133:298-308

Panero WR (2010) First principles determination of the structure and elasticity of hydrous ringwoodite. J Geophys Res 115:B03203. doi:10.1029/2008JB006282

Panero WR, Smyth JR, Pigott JS, Liu Z, Frost DJ (2013) Hydrous ringwoodite to 5 $\mathrm{K}$ and $35 \mathrm{GPa}$ : multiple hydrogen bonding sites resolved with FTIR spectroscopy. Amer Mineral 98:637-642. doi:10.2138/am.2013.3978

Pearson DG, Brenker FE, Nestola F, McNeill J, Nasdala L, Hutchison MT et al (2014) Hydrous mantle transition zone indicated by ringwoodite included within diamond. Nature 507:221-224. doi:10.1038/nature13080

Perdew JP, Burke K, Ernzerhof M (1996) Generalized gradient approximation made simple. Phys Rev Lett 77:3865-3868

Schweiger E, Sharma M, Gygi F, Galli G (2008) Melting of ice under pressure. Proc Nat Acad Sci 105:14779-14783

Shimizu H, Utada H, Baba K, Koyama T, Obayashi M, Fukao Y (2010) Threedimensional imaging of electrical conductivity in the mantle transition zone beneath the North Pacific Ocean by a semi-global induction study. Phys Earth Planet Inter 183:252-269

Smyth JR, Kawamoto T, Jacobsen SD, Swope RJ, Hervig RL, Holloway JR (1997) Crystal structure of monoclinic hydrous wadsleyite $\left[\beta-\left(\mathrm{Mg}, \mathrm{Fe}_{2} \mathrm{SiO}_{4}\right]\right.$. Amer Mineral 82:270-275

Sun W, Yoshino T, Sakamoto N (2015) Hydrogen self-diffusivity in single crystal ringwoodite: implications for water content and distribution in the mantle transition zone. Geophy Res Lett 42:06448. doi:10.1002/2015GL064486

Tse JS (2002) Ab initio molecular dynamics with density functional theory. Ann Rev Phys Chem 62:249-290. doi:10.1146/annurev.physchem.53.090401.105737

Tsuchiya J, Tsuchiya T (2009) First principles investigation of the structural and elastic properties of hydrous wadsleyite under pressure. J Geophys Res 114: B02206. doi:10.1029/2008JB005841

Verma, AK, Karki, BB (2009) First-principles simulations of native point defects and ionic diffusion in high-pressure polymorphs of silica. Phys Rev B 79:214115.

Yoshino T, Matsuzaki T, Shatskiy A, Katsura T (2009) Earth and planetary science letters. Earth Planet Sci Lett 288:291-300. doi:10.1016/j.epsl.2009.09.032.

\section{Submit your manuscript to a SpringerOpen ${ }^{\circ}$ journal and benefit from:}

- Convenient online submission

- Rigorous peer review

- Immediate publication on acceptance

- Open access: articles freely available online

- High visibility within the field

- Retaining the copyright to your article

Submit your next manuscript at $\gg$ springeropen.com 